\title{
El final de las lenguas y de las culturas epigráficas paleoeuropeas
}

\author{
The end of Palaeoeuropean \\ languages and epigraphic cultures
}

\author{
Francisco Beltrán Lloris \\ Grupo Hiberus | Instituto Universitario \\ de Investigación en Patrimonio y \\ Humanidades | Universidad de Zaragoza \\ fbeltran@unizar.es
}

\begin{abstract}
Resumen: Durante los siglos II y I a. E. la cultura escrita paleoeuropea alcanzó su máxima intensidad, diversificación y expansión geográfica, pero también empezó a experimentar la presión de la pujante cultura escrita latina que terminó por imponerse sobre ella hasta provocar su extinción. El papel de Roma en este proceso fue determinante al crear un marco común de relación en el occidente europeo, fomentar la cultura escrita y contribuir a difundir nuevos estímulos, muchos de ellos de origen helenístico pero reelaborados en Roma, entre los que destaca el uso de las inscripciones públicas como medio de comunicación social. Las reacciones de las culturas locales fueron muy variadas, pero siempre con predominio de la lengua y las escrituras vernáculas en las manifestaciones epigráficas.
\end{abstract}

Palabras clave: Culturas epigráficas paleoeuropeas. Romanización. Latinización. Lenguas y escrituras paleoeuropeas.

Abstract: During the $2^{\text {nd }}$ and $1^{\text {st }}$ centuries BCE the Palaeoeuropean written culture reached, on the one hand, its maximum intensity, diversification and geographic expansion, but, on the other, it underwent the pressure of the powerful Latin written culture that ended up imposing itself until causing the extinction of the written use of Palaeoeuropean languages. The role of Rome in this process was decisive in creating a common framework of relations in western Europe, promoting written culture and helping to spread new stimuli, many of them of Hellenistic origin but reworked in Rome, among which the use of public inscriptions as a means of social communication. The reactions of local cultures varied greatly, but always with predominance of the vernacular languages and writings in the epigraphic manifestations.

Key words: Palaeoeuropean epigraphic cultures. Romanization. Latinization. Palaeoeuropean languages and writings.

Recepción: 04.05.2020 | Aceptación: 13.05.2020

Financiación: Este trabajo se ha realizado en el seno del proyecto El final de las escrituras paleohispánicas (FFI2015-63981-C3-3-P), financiado por Ministerio de Economía y Competitividad. 


\section{Roma y el final de las culturas escritas vernáculas}

La cultura escrita en lenguas locales del occidente europeo experimenta un desarrollo un tanto paradójico durante los siglos II y I a. E., pues, por una parte, alcanza entonces su máxima intensidad, diversificación y expansión geográfica, pero, por otra, lo hace bajo la creciente presión de la latina que, en el plazo de esos dos siglos, se impondrá de manera aplastante hasta provocar su extinción casi absoluta en los primeros decenios de la Era. ${ }^{1}$

\subsection{Culturas epigráficas: paleoeuropeas y romana}

Las diversas culturas epigráficas que se desarrollan el Mediterráneo occidental durante el I milenio deben ser entendidas no como meras series de textos escritos en un idioma y un alfabeto determinados, sino como conjuntos de saberes y prácticas comunicativas, a menudo con un elevado valor simbólico, que combinan lengua, escritura y soporte para consignar o transmitir mensajes en un contexto social e ideológico determinado.

Las más antiguas emergen a comienzos del siglo VIII a. E., cuando el alfabeto, introducido por fenicios y griegos a fines del IX, empieza a difundirse en medios indígenas y se adapta progresivamente a más de veinte idiomas vernáculos generando casi otros tantos sistemas de notación. ${ }^{2}$ Estas lenguas fragmentarias, sin literatura conservada ${ }^{3} \mathrm{y}$ atestiguadas solo epigráficamente, así como sus correspondientes escrituras e inscripciones son las que ahora denominamos paleoeuropeas. ${ }^{4}$ La producción escrita en estas lenguas es fruto de culturas epigráficas de gran personalidad, con ritmos cronológicos y volúmenes de producción muy diferentes, y se caracteriza por su diversidad, baja

1 Sobre Roma y las culturas epigráficas del Mediterráneo occidental, Beltrán 1995; Beltrán y Díaz 2018.

2 Los epígrafes más antiguos son fenicios, datan de fines del IX a. E. y proceden del Mediterráneo central y del sur de Hispania (Amadasi 2019a, 47; Zamora 2013, 370-371; 2019, 59 n. 24: Castillejos de Alcorrín (?) y la Rebanadilla). El documento más temprano en alfabeto griego es el polémico grafito de Osteria dell'Osa, anterior a 770 a. E., en lengua griega para la mayoría de estudiosos (Bietti Sestieri, De Sanctis y La Regina 1990, 83-88; La Regina 2012; Boffa 2015), aunque latina para algunos (Colonna 2005; Bellelli y Benelli 2018, 27). El más antiguo epígrafe latino parece ser el grafito del Esquilino, CIL $\mathrm{I}^{2}$ 2901a, datado en las primeras décadas del siglo VII a. E. (Colonna 2014).

3 El texto paleoeuropeo no epigráfico más relevante es el etrusco liber linteus de Zagreb, de 230 líneas de extensión; Belfiore 2010.

4 La denominación fue propuesta en el coloquio AELAW de Roma, 2019; véase al respecto, la introducción a este volumen. 
intensidad y reducida extensión geográfica, limitada a Italia —con Sicilia-, Hispania y Galia. Esta fase finaliza a fines del siglo I a. E. cuando las lenguas locales dejan de escribirse con regularidad, ceden su lugar al latín y se extinguen en su mayoría: las pocas que sobreviven, como el vascónico-aquitano, lo hacen sin dejar rastro escrito. ${ }^{5}$

Con el Principado empieza una nueva etapa en la que la cultura escrita latina deja de ser una más, aunque prominente, entre las occidentales para convertirse en exclusiva. Una cultura dotada de una rica tradición literaria, una notable producción escrita y un elevado grado de homogeneidad fruto de la unificación de Occidente bajo el poder político de Roma: un poder basado en presupuestos culturales e ideológicos bien definidos que encontraron precisamente en la nueva cultura epigráfica estimulada por Augusto un poderoso canal de expresión. ${ }^{6} \mathrm{El}$ impacto sobre los usos lingüísticos y la práctica escrita fue enorme: el latín fue adoptado como idioma materno por casi todos los pobladores de Italia, Hispania y Galia - la Sicilia griega es caso aparte-; alcanzó la condición de medio de comunicación general, literario y escrito en todo Occidente; y se convirtió en instrumento de alfabetización de las sociedades ágrafas que moraban en las regiones más alejadas del Mediterráneo. En cuanto a las lenguas vernáculas, desaparecieron casi sin excepción del registro escrito. Hay que esperar a los siglos III y IV d. E. para que vuelva a escribirse una lengua local en Europa y ello, en los márgenes externos del mundo romano y recurriendo a sistemas de escritura de matriz latina pero nuevos y con un claro afán de afirmación identitaria frente a Roma: las runas germánicas y el ogam irlandés. ${ }^{7}$

Este capítulo pretende identificar las líneas de fuerza y los rasgos que conforman la última fase de las culturas escritas paleoeuropeas antes de ser reemplazadas por la romana. Obviamente, este proceso no puede disociarse del ascenso de Roma a potencia hegemónica de Occidente, que aun siendo una condición necesaria para el triunfo del latín, no lo explica por completo, pues también Roma dominó Oriente durante siglos sin que su lengua llegara a

5 La existencia de algunos textos en vascónico - leyendas monetales y algún epígrafe - no puede ser excluida. Sobre el vascónico-aquitano, Gorrochategui e. p. y en este mismo volumen; Gorrochategui y Vallejo 2019, 361-365. A diferencia de Europa, en el norte de África tanto el púnico como el líbico persistieron hasta el final de la antigüedad.

6 Alföldy 1991; Woolf 1996.

7 Sobre runas y ogam pueden consultarse los capítulos de T. Looijenga y D. Stifter en este mismo volumen. 
imponerse. ${ }^{8}$ El triunfo del latín en Occidente se vio favorecido por la ausencia de lenguas de comunicación general, la fecha más tardía de alfabetización, una limitada difusión social de la escritura y la precariedad o inexistencia de tradiciones literarias locales; pero, además, resultaron determinantes la potente emigración itálica y las amplias políticas de concesión de la ciudadanía romana que apenas se dieron en oriente durante los siglos I y II d. E. ${ }^{9}$

\subsection{Delimitación del periodo: fines del III - fines del I a. E.}

La fijación del final de esta fase no ofrece problemas pues coincide con la afirmación del Principado y el abandono generalizado de las lenguas paleoeuropeas, cuyo uso escrito sobre soportes duraderos se hizo excepcional a partir de Augusto. A lo largo del siglo I d. E. se redactan esporádicamente epígrafes en etrusco, osco, ibérico, celtibérico, lusitano y, desde luego, en galo, cuyo empleo persiste hasta el siglo II d. E. o más tarde, ${ }^{10}$ pero no existen ya culturas epigráficas paleoeuropeas como tales.

Mucho más problemático resulta determinar el momento inicial pues no puede asociarse con ningún hito de alcance general en Occidente. Que el desenlace de esta fase fuera la latinización de la cultura escrita y la retracción de las lenguas locales occidentales concede al contacto con Roma un papel clave en su definición: sin embargo este contacto no se produjo en Italia, Hispania y Galia de manera simultánea, ni en las mismas condiciones, ni con resultados homogéneos. De hecho, la variedad de dinámicas históricas imperante durante esta época en el Mediterráneo occidental - en contraste con el devenir histórico mucho más integrado que caracteriza al Principado- ha dado lugar a diferentes tradiciones de periodización, en las que la afirmación de la hegemonía romana no desempeña siempre el mismo papel.

En el ámbito cartaginés suele distinguirse una fase arcaica hasta mediados del VI a. E., seguida de la propiamente púnica que termina, obviamente,

8 Sobre el latín en el oriente griego Rochette 1997; 2010.

9 Sobre la latinización de Occidente, entre otros: Adams 2003a; 2003b; Beltrán 2004a (para Hispania); Beltrán e. p. (sobre latinización y romanización).

10 El epígrafe galo más reciente es probablemente la teja de Châteaubleau que, según Lambert 1998a, 61 (a partir de Pathuisot 1997, 29) apareció en un pozo de fines del siglo II d. E. entre rellenos “impossibles de dater", quizás de fines del III o comienzos del IV d. E. "d’après certains exemplaires de céramique commune". Casi todas las tejas datadas de Châteaubleau se fechan en II d. E. (Lambert 1998b, 119-120, 124). 
con la destrucción de Cartago en 146 a. E. y da paso a la púnico-romana. ${ }^{11}$ En Hispania y Galia, la conquista romana, a partir de fines de III a. E. y de fines del II a. E. respectivamente, no solo marca también un claro punto de inflexión histórico, sino que coincide con el inicio de varias de las culturas epigráficas locales. En Roma, la periodización epigráfica tiende a superponerse a la histórica con una etapa arcaica que cubre Monarquía y República primitiva hasta comienzos del siglo III a. E., y otras dos que coinciden con la República media, hasta el último tercio del II a. E., y con la tardía, a partir de esa última fecha. ${ }^{12}$ Así, pese a las diferencias locales, se aprecia en todos estos escenarios un lapso entre fines del III y fines del II a. E. que resulta significativo desde el punto de vista histórico y también para la cultura escrita.

No ocurre lo mismo en el resto de Italia, en donde la periodización tradicional de las culturas epigráficas no depende del momento en el que se establece el control romano, generalmente a lo largo del siglo III a. E. Así, en el caso de las dos epigrafías italianas más importantes, la etrusca y la sabélica, ${ }^{13}$ pero también de la siciliana, ${ }^{14}$ se contraponen solo dos etapas, una arcaica -VIII/VII a V a. E.- y otra reciente - IV a I a. E.-, que, a cambio, no parecen tan adecuadas para articular otras epigrafías itálicas como la mesápica - VI-II/I a. E.—, en la que el tránsito del siglo IV al III a. E. resulta más significativo como hito periodizador, ${ }^{15}$ ni para zonas como la medio-adriática muy marcadas por la conquista romana. ${ }^{16}$

Pero el período c. 200-100 a. E. no solo resulta significativo en el devenir histórico y en la cultura escrita de Roma y de otras regiones de Italia, Hispania y Galia. Contempla, además, una serie de fenómenos relevantes: por una parte, el primer impacto de la escritura y de la lengua latinas sobre las culturas epigráficas locales de Italia, Hispania y Galia; y, por otra, un claro cambio de tendencia en la intensidad, la difusión y la diversidad de la práctica epigráfica y de la escritura en general. Este conjunto de rasgos específicos es el que permite abordar de una manera conjunta las dinámicas epigráficas que se

11 Una periodización comparada de las diferentes áreas púnicas africanas en D’Andrea 2013, 18.

12 Así, Panciera 2007, 100.

13 Poccetti 2018; Benelli 2018.

14 Prag 2018.

15 Marchesini 2009, 144; De Simone y Marchesini 2002 periodizan la epigrafía mesápica en cuatro fases (seguidas por Morandi 2017, 292): arcaica (fines VI-inicio V a. E.), clásica (V-IV a. E.), helenística (III-II a. E.) y republicana (II-I a. E.). 
desarrollan durante este periodo y considerarlas como un fenómeno dotado de una cierta coherencia.

\subsection{Rasgos definidores: contacto con el latín, expansión, intensifica- ción, diversificación}

El impacto del latín sobre las lenguas paleoeuropeas, aun con intensidades diferentes, es evidente a partir de fines del siglo III a. E. Se percibe en la producción de inscripciones bilingües en Italia e Hispania: etruscas -el grupo más numeroso con una treintena de inscripciones- en II y I a. E., con algún ejemplar en IV-III a. E.; oscas, entre fines del III y fines del I a. E.; véneticas, en II-I a. E.; célticas cisalpinas - 'galo-etruscas' y galo-latinas-, entre 200 y 100 a. E.; ibéricas, en monedas e inscripciones, durante los siglos II y I a. E.; y lusitanas, entre fines del I a. E. y el I d. E. ${ }^{17}$ Y se aprecia también en el empleo del alfabeto latino para transcribir lenguas locales: entre III y I a. E. en Italia, -etrusco, osco, umbro, falisco y venético-y a partir del I a. E. en Hispania -celtibérico, lusitano e ibérico ${ }^{18}$ - y Galia. ${ }^{19}$ Todo ello subraya el prestigio y la difusión de la lengua de Roma durante los siglos que preceden a su afirmación hegemónica en el cambio de Era. En la misma dirección apunta el hecho de que los numerosos itálicos que participan en el ejército y en el comercio tardorrepublicanos nunca utilicen sus lenguas vernáculas por escrito en tierras provinciales y recurran siempre al latín como lengua común escrita. ${ }^{20}$ Esta tendencia, compartida por todas las culturas epigráficas paleoeuropeas, entre las que son contadísimos los epígrafes documentados fuera de su contexto lingüístico, ${ }^{21}$ justifica su caracterización como locales frente a la fenicia, la griega o la latina.

17 Estarán 2016, 39-40 y 84-94; Simón 2019c.

18 Simón 2019b y 2019c.

19 I. Simón en este mismo volumen y Estarán e. p.

20 La única excepción son los hitos terminales etruscos de Zaghouan (Túnez). ET Af. 8.1-8 (Zaghouan); sobre el presunto - y poco fundamentado- influjo de la lengua osca en el latín de Hispania, Beltrán y Velaza e. p.; Estarán 2019.

21 Habría que exceptuar el uso del etrusco fuera de su solar originario debido a la expansión por Italia y otras zonas en época arcaica sobre todo. Otro caso excepcional es la losa celtibérica aparecida en la necrópolis púnica de Ibiza (IB.01.01); al respecto, Beltrán 2011, 48-49. Los restantes epígrafes aparecidos fuera de contexto, realizados sobre objetos de pequeño tamaño y fácilmente transportables, son importados: Beltrán y Estarán 2011, 19, 22 (materiales ibéricos y celtibéricos); Remesal y Musso 1991 (materiales etruscos en Hispania); Poli 2003 (posible epígrafe osco en el sur de Francia)... 
En lo que respecta al cambio de tendencia en la producción epigráfica se plasma en tres fenómenos que se desarrollan fundamentalmente a partir del siglo II a. E. y que marcan diferencias notables respecto de las fases previas. ${ }^{22}$

(i) Intensificación de la cultura escrita hasta duplicar - al menos- en estas dos centurias la producción epigráfica de las cinco anteriores.

(ii) Expansión geográfica de la escritura que, de estar confinada en los asentamientos coloniales fenicios y griegos, gran parte de Italia y el litoral oriental ibérico, se difunde en el curso del siglo II a. E. por el resto de Italia, el interior y el occidente hispanos, y las Galias.

(iii) Diversificación de los usos epigráficos y proliferación de las inscripciones monumentales destinadas a una exposición pública, un hecho -muy evidente en Roma - de enorme significación para la cultura escrita por transformar las inscripciones en medido de comunicación social comunitaria frente al uso abrumadoramente privado que la escritura había tenido hasta entonces.

Estos tres fenómenos, de los que nos ocuparemos en los dos siguientes apartados, son propios de los siglos II y I a. E., y contemporáneos de la definitiva afirmación de la hegemonía romana en Italia, tras la Guerra Social, y de la expansión por Hispania y Galia. Coinciden, además, no solo con un uso creciente del alfabeto latino para escribir las lenguas locales y con la producción de inscripciones bilingües, sino con un incremento de las inscripciones redactadas en latín por romanos e indígenas y con la incorporación por las culturas epigráficas locales de rasgos propios de la romana.

Este contexto fuerza a interrogarse acerca del papel desempeñado por Roma en la conformación de esta última fase de las culturas epigráficas paleoeuropeas. En unos casos las aportaciones romanas son evidentes, pero en otros no resultan tan claras o apenas se perciben, de ahí la polémica, muy ligada a la discusión sobre la noción de 'romanización,'23 acerca de si hay que

22 Significativamente, Panciera 2007, 84 a la hora de identificar criterios para fijar una nueva etapa de la comunicación epigráfica romana se planteaba estas cuatro preguntas: "con quale frequenza si faccia ricorso ad essa; per farne quale uso; da parte di chi; in quali forme non solo testuali, ma anche visive". Es decir: intensidad de la producción epigráfica, tipos de usos, identificación de los comitentes (y destinatarios) y características formales del epígrafe. 
atribuir a Roma un rol protagonista en este proceso ${ }^{24}$ o si se trata de un fenómeno más general y vago de helenización ${ }^{25} \mathrm{o}$ 'mediterraneización'. ${ }^{26}$

Esta dicotomía resulta un tanto artificiosa, pues el proceso de 'romanización temprana' de los siglos II-I a. E, difiere profundamente del que se abre a partir del Principado. Conlleva, sin duda, transformaciones relevantes y profundas, pero en contextos en los que predominan los rasgos locales en la lengua, en la religión o en la cultura, y en los que Roma, particularmente en las provincias occidentales, no solo canaliza tendencias y formas culturales propias sino también otras de procedencia helenística, itálica o de otras áreas mediterráneas, previamente reelaboradas en muchos casos. ${ }^{27}$ Sobre esta cuestión volveremos al final del capítulo.

Por todo ello esta fase no debe reducirse a un mero proceso de latinización o de romanización de la cultura escrita. Es mucho más. Es el periodo más rico y productivo de las culturas epigráficas paleoeuropeas e, incluso, el de surgimiento de algunas de ellas, aunque, paradójicamente, sea también el del comienzo de su declive en beneficio de la cultura epigráfica latina. No hay contradicción alguna en que muchas de las culturas epigráficas paleoeuropeas surjan o alcancen ahora su fase más expansiva, productiva y diversificada, precisamente antes de desaparecer. El crecimiento de la cultura escrita es un fenómeno general que afecta no solo a la paleoeuropea sino también a la latina $y$, probablemente, a la helena y la púnica, y que se produce de manera sostenida y sin solución de continuidad a partir de los siglos III y II a. E., según las áreas, hasta alcanzar con Augusto un incremento exponencial cuyo núcleo duro se encuentra precisamente en las regiones que protagonizan la última etapa de las epigrafías paleoeuropeas: Italia, Hispania y Galia meridional. La diferencia es que esa producción escrita forma parte ahora de una nueva cultura epigráfica: la romana del Principado. ${ }^{28}$

\footnotetext{
24 Beltrán y Díaz 2018.

25 Prag 2013.

26 Keay 2013, 317-318 lo expresa así: "the prevalent cultural convergence that was taking place across the western Mediterranean" (ver nota siguiente).

27 Sobre la romanización temprana, Beltrán 2003 (Beltrán 1999a: 'early Romanization'). Keay 2013, 317-318 señala propósito de los iberos que si hubo helenización en los siglos III-II a. E., "it has to be understood primarily through a Roman filter and in terms of long-standing regional contexts". Alföldy 1991.
} 


\section{Volumen, ritmos, geografía}

\subsection{Datación y cuantificación}

El estado actual de los estudios paleoeuropeos no facilita una aproximación diacrónica a cada una de las culturas epigráficas ni, mucho menos, a todas en conjunto. Escasean las bases de datos actualizadas y exhaustivas, ${ }^{29} \mathrm{y}$ ello limita las posibilidades de ordenar, clasificar y cuantificar los materiales escritos. Estos, además, son difíciles de datar con precisión, sobre todo cuando carecen de contexto arqueológico o han sido reutilizados - circunstancias muy habituales-, salvo en el caso etrusco que por su larga duración y elevado volumen de inscripciones admite seriaciones. En los restantes resulta necesario conformarse a menudo con horquillas temporales que pueden ser muy amplias y abarcar centurias enteras.

En las cuantificaciones debe valorarse, además, la entidad de los epígrafes, pues últimamente tiende a computarse la totalidad de los rótulos, incluidos fragmentos brevísimos, con tan pocos signos o letras que a veces no permiten identificar la lengua en la que están escritos o discriminar si son de carácter grafemático o pseudo-escritura. De nuevo se aparta de esta tendencia la epigrafía etrusca en la que por su riqueza -más de 10.000 inscripciones-, no suelen contabilizarse los rótulos de una a tres letras, que, seguramente, haya que contar por centenares, si no por miles. La inclusión de los rótulos brevísimos, casi siempre grafitos sobre cerámica, distorsiona los números globales manejados hasta ahora: por ejemplo, la serie celtibérica, con dos centenares de epígrafes de una cierta entidad, se incrementa hasta más de 500; la gala, se evalúa ahora en un millar de los que más de 500 son breves y lo mismo ocurre con la venética, con 700 epígrafes - 200 fragmentarios o brevísimos- y aún más con la lepóntica o la rética, con c. 400 rótulos, muchos cortísimos, y abundantes pseudoepígrafes en el caso de la segunda. ${ }^{30}$

Pese a estas dificultades y limitaciones constituye, sin duda, un avance positivo el censo emprendido por la red AELAW que permite una primera

29 Entre las bases de datos paleoeuropeas hay que señalar Hesperia, todavía incompleta, dedicada a las lenguas paleohispánicas (Hesperia, $\langle\underline{\mathrm{http}}$ ://hesperia.ucm.es $>$ ) y otras dos consagradas a las inscripciones lepónticas (Lexicon Leponticum, $<$ http://www.univie. ac.at/lexlep/wiki>) y réticas (Thesaurus Inscriptionum Raeticarum, <www.univie.ac.at/ raetica/wiki/Main Page>). Sobre las bases de datos epigráficas, De Santis y Rossi 2019.

$30 \mathrm{Al}$ respecto, además de la base de datos AELAW (<http://aelaw.unizar.es/database/ inscriptions $>$, en curso), véanse las diversas contribuciones de la sección central de este volumen, todas con cifras. 
aproximación, aunque no sea ni exhaustiva ni exacta, a los grandes números y cronologías de las culturas epigráficas paleoeuropeas. El volumen total estimado, incluidos todos los rótulos brevísimos salvo los etruscos, supera las 18.000 inscripciones. $^{31}$

\subsection{Intensificación}

Un total de 18.000 inscripciones -8.000 sin las etruscas-, a lo largo de ocho siglos, siendo además muchas breves o brevísimas, supone una intensidad productiva baja, aunque ello dependa mucho del término de comparación. Las 10.000 inscripciones etruscas producidas en un territorio no muy extenso durante unos 800 años resisten perfectamente la comparación con las 10.000 inscripciones fenicias realizadas en todo el Mediterráneo en el curso de un milenio y medio, ${ }^{32}$ máxime procediendo más de 6.000 del tophet de Cartago. ${ }^{33}$ A cambio, las culturas escritas paleoeuropeas se encuentran muy por debajo de la producción de las dos epigrafías clásicas: la griega — de la que no existe una cuantificación fiable - y la romana, que en algunas bases de datos supera las 500.000 inscripciones. ${ }^{34}$ Es cierto que en ambos casos los escenarios y los lapsos cronológicos son mucho más amplios, pero aun ciñendo la comparación al ámbito en el que se desarrolla la epigrafía paleoeuropea - Hispania, Galia, Italia-, resulta evidente la desproporción con la romana: frente a las 18.000 paleoeuropeas realizadas entre VIII y I a. E., las latinas producidas en I-III d. E. se estiman en unas 200.000 y en otras 80.000 para la Antigüedad Tardía, ${ }^{35}$ respectivamente, diez y cuatro veces más que las paleoeuropeas.

Pues bien, de esas $c$. 18.000 inscripciones paleoeuropeas un volumen muy elevado, aunque difícil de contabilizar con precisión, fue producido a partir de fines del siglo III a. E. Entre las etruscas, con elevado peso específico en el

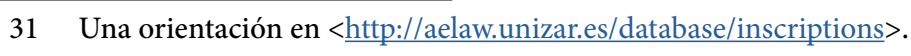

32 Según Corpus Inscriptionum Phoenicarum necnon Poenicarum (CIP) $<$ http://cip.cchs.csic.es $>$.

33 Amadasi 2019b, 176.

34 Epigraphik-Databank Clauss-Slaby (EDCS) registra un total de 520.061 entradas, aunque

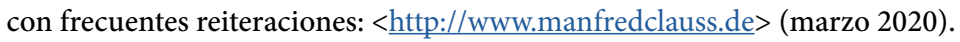

35 Las cifras están extraídas del cómputo por provincias realizado a partir EDCS en 2014 (Beltrán 2015a, 136-140): sobre el total de c. 277.000, incluidas las tres Hispanias, las cuatro Galias, las provincias alpinas y las tres grandes islas que delimitan el Mar Tirreno, unas 5.000 son de fecha republicana (Solin 1999, 391-393; Salomies 2015, 159); convencionalmente atribuimos un $30 \%$ del total al periodo tardo-antiguo, proyectando las cifras deducidas del Epigraphic Database Bari (EDB) que en la actualidad reporta más de 40.000 inscripciones cristianas en la Roma de los siglos III a VIII d. E. (<http://www.edb.uniba.it $>)$ sobre un total que debe superar las 120.000 inscripciones. 
cómputo total, unas 8.000 se datan en III-I a. E., de las que más de 5.000 son posteriores a c. 220 a. E. en Etruria septentrional y un número no cuantificado en Etruria meridional, menos productiva en esta época. ${ }^{36} \mathrm{~A}$ ellas deben añadirse más de 3.000 de las 4.000 inscripciones extra-itálicas: 1600 de las c. 2.250 inscripciones ibéricas, ${ }^{37}$ las 500 celtibéricas, las 6 lusitanas y las mil galas, y un número difícil de precisar de las restantes 4.000 inscripciones de Italia. ${ }^{38}$ Eso supone que el volumen de epígrafes producido a partir de fines del siglo III a. E., con la estimación más prudente, equivale al de las cinco centurias previas y representa no menos del $50 \%$ del total de la epigrafía paleoeuropea, porcentaje que asciende al $70 \%$ al menos si se incluye la totalidad del siglo III a. E.

Este incremento no es un fenómeno solo paleoeuropeo. La producción epigráfica siciliana, mayoritariamente en griego, ${ }^{39}$ también crece en el siglo II a. E. ${ }^{40}$ y la latina, según ciertos cálculos, pasa de $c .600$ inscripciones en VI-III a. E. a c. 3.500 en II-I a. E., ${ }^{41}$ sin duda en buena parte gracias a la expansión por Italia. En el caso fenicio resulta más difícil de precisar esta evolución, si bien las estelas de tophet parecen incrementarse en la fase clásica del santuario (IV-II a. E.). ${ }^{42}$

36 Estimación expuesta por E. Benelli en la Segunda AELAW Training School, Pre-Roman languages and inscriptions of Italy (Verona, 2018) y confirmada en comunicación epistolar. El cálculo se basa en Etruskische Texte (Meiser 2014): de las casi 11.000 inscripciones recogidas en esta obra y en trabajos posteriores, unas 9.000 se datan entre IV y I a. E., de las que no más de mil parecen fecharse en el siglo IV a. En un trabajo posterior aún inédito, E. Benelli ha realizado un cómputo más preciso a partir de las inscripciones etruscas septentrionales (+6.000), entre las que más de 5.000 son posteriores a 220 a. E. Agradezco muy cordialmente a Enrico Benelli su generosidad al compartir conmigo esta información y autorizarme a incluirla en este trabajo.

37 Velaza 2018, 169-171.

38 No existe un cómputo periodizado de las inscripciones no etruscas de Italia.

39 Casi todas las inscripciones élimas y sículas se datan entre VI y V a. E.

40 Prag 2018, 132-136.

41 Solin 1991, 391-393; Salomies 2015, 159.

42 Amadasi y Zamora, 2013. D’Andrea 2013, 331-332 recoge 6.000 inscripciones procedentes del tophet de Cartago y otras 700 más de otros santuarios norteafricanos (incluidas las inscripciones latinas, griegas y líbicas), sobre todo de Costantina (mediados III a. E. - primera mitad I d. E.: 450 epígrafes), Maktar (I a. E. - II d. E.: +150) y Guelma (II a. E. - II d. E.?: c. 70), dato este que parece reforzar la idea de que las inscripciones se incrementan notablemente tras IV-III a. E. 
En definitiva y aun con ritmos regionales desiguales, en el curso de los siglos III, y sobre todo II y I a. E. la producción epigráfica experimentó un notabilísimo incremento en el occidente europeo.

\subsection{Italia, Hispania, Galia: ritmos y cartografía}

A fines del siglo III a. E. la cultura escrita era un fenómeno exclusivo de las ciudades fenicias y griegas, de muchas regiones de Italia y de la fachada oriental de Hispania. ${ }^{43}$ En las dos siguientes centurias, sin embargo, se extendió por las áreas aún ágrafas de Italia, por el interior y el occidente de Hispania y por las Galias.

En el caso de Hispania esta expansión se aprecia con claridad comparando la cartografía de los epígrafes producidos en IV-III y en II-I a. E. ${ }^{44}$ Los primeros se circunscriben, con densidades muy bajas, al litoral mediterráneo ibérico y algunos puntos del sur. ${ }^{45}$ Los producidos durante II-I a. E., a cambio, no solo se adensan en las regiones interiores ibéricas, sino que se difunden por el valle medio del Ebro, la Celtiberia y todo el valle del Guadalquivir, aquí con una fuerte presencia de letreros monetales en latín y púnico, pero también ibéricos en la parte oriental. Solo el cuadrante noroccidental permanece ágrafo. En la costa mediterránea de la Hispania Citerior se identifican además ciudades con apreciable densidad epigráfica: ibérica en Sagunto, latina en Cartago Nova, ibérica y latina en Tarraco, y griega además en Emporion, ${ }^{46}$ incluidas algunas bilingües. ${ }^{47}$ Resulta difícil fijar los ritmos cronológicos precisos de la difusión de la escritura, aunque en el interior ibérico y en el territorio celtibérico se produce a partir de mediados del siglo II a. E. sobre todo. ${ }^{48}$ Da la impresión, pero es solo una impresión, de que la mayor parte de la producción epigráfica celtibérica se concentra en la segunda mitad o el final del II a. E. y en el I a. E., una datación probablemente extensible a buena parte de las inscripciones ibéricas y latinas, sobre todo las realizadas sobre piedra. Más tardía aún es la media docena de epígrafes lusitanos — todos ellos religiosos, en alfabeto

43 Recuérdese que la epigrafía del Sudoeste hispano, surgida hacia VII/VI a. E., cesa (casi) por completo en IV a. E.; de $\mathrm{Hoz} 2010$.

44 Véanse los mapas del Banco de Datos Hesperia relativos a los epígrafes de los siglos IV-III a. E. y del II a. E. en adelante (<http://hesperia.ucm.es/img/Mapas Cronologicos Inscripciones 3.jpg > ).

45 Véase la contribución de N. Moncunill y J. Velaza en este mismo volumen.

46 Sobre la epigrafía latina hispana republicana, Díaz 2008.

47 Estarán 2016, 293-388.

48 Véase F. Beltrán y C. Jordán en este mismo volumen, además de Velaza e. p. 
latino y sobre soportes pétreos - y los numerosos teónimos declinados en esta lengua de las inscripciones latinas del Principado, ninguno anterior al I a. E. ${ }^{49}$

La Galia también se incorpora en esta fase a la cultura escrita. ${ }^{50}$ Pero no desde fines del siglo III a. E., como se defendía tradicionalmente, sino más tarde: ahora los primeros grafitos se datan en II a. E. y las primeras inscripciones sobre piedra a mediados de la centuria. ${ }^{51} \mathrm{El}$ desfase respecto de la fundación de Massalia, hacia 600 a. E., cuestiona el papel de la cultura escrita helena en el surgimiento de la gala, ${ }^{52}$ pese a utilizar el alfabeto griego. Y difiere mucho de la ibérica en la que se observan interesantes correspondencias con la helena -tipos epigráficos compartidos como las cartas sobre láminas de plomo o el empleo de una variante del alfabeto griego en el siglo IV a. E.- - y una mayor proximidad temporal entre la fundación de las colonias griegas del golfo de Rosas, hacia 600 a. E., y las primeras inscripciones ibéricas de fines del V a. E. El alfabeto griego predomina en la epigrafía gala hasta época de César aproximadamente, cuando se produce el paso al latino con más de medio siglo de retraso respecto de la conquista romana de la Narbonense a fines del siglo II a. E. Las inscripciones galo-griegas, en su mayoría producidas en II-I a. E., se concentran en el bajo curso del Ródano, mientras que las galo-latinas, a partir de mediados del I a. E., se distribuyen por gran parte de Galia. ${ }^{53}$

El núcleo duro de la cultura escrita del I milenio a. E. se encuentra en Italia, con 14.000 de las 18.000 inscripciones paleoeuropeas —incluidas las más de 10.000 etruscas - a las que hay que sumar 5.000 más latinas. Los cambios que se perciben a partir de fines del III a. E suponen, en muchos casos, el relevo de la lengua local por el latín o la introducción de la cultura epigráfica latina en áreas con poca tradición escrita o ágrafas. Así, en la región medio-adriática, donde tras la fase paleosabélica - VII-V a. E.- - las inscripciones brillan por su ausencia, ${ }^{54}$ se recupera la producción epigráfica en III a. E. y con más intensidad en II a. E., pero ya en latín, primero en las áreas afectadas por la

49 Simón 2019a.

50 Mullen y Ruiz Darasse 2018. Permanece abierta la discusión acerca de la existencia de documentos en un celta británico diferente del galo, Lambert 1994, 17-19; Mullen 2007.

51 Bats 1988, 2004 y 2011.

52 A. Mullen y C. Ruiz Darasse en este mismo volumen.

53 Mullen y Ruiz Darasse 2018, 32.

54 Poccetti 2018. 
colonización romana y luego en medios indígenas. ${ }^{55}$ Una situación semejante se produce en regiones de la Cisalpina como Liguria a partir del siglo I a. E. ${ }^{56}$

\section{Diversificación de tipos: el desarrollo de la epigrafía pública}

La cultura escrita se desarrolló entre los siglos VIII y III a. E. como un fenómeno comunicativo interpersonal de carácter más bien privado y socialmente restringido. Pero a partir del II a. E. la diversificación funcional de las inscripciones y en concreto el desarrollo de la epigrafía monumental y pública inaugura una nueva etapa marcada por un empleo de la escritura como medio de comunicación social que alcanzará su culminación a partir de Augusto.

Naturalmente, las inscripciones públicas no surgen en esta época. Las hay y muy conspicuas en centurias previas: además de las inscripciones griegas de Magna Grecia y Sicilia, ${ }^{57}$ cabe mencionar la estela fenicia de Nora, en Cerdeña (VIII a. E.); ${ }^{58}$ el centenar de grandes losas funerarias del Sudoeste peninsular (VI-V a. E);' monumentos funerarios paleosabélicos como el 'Guerriero di Capestrano' (VI a. E.); ${ }^{60}$ los epígrafes exteriores de las tumbas de Orvieto (mediados del VI a. E.); ${ }^{61}$ o los bloques ibéricos de Ullastret, anteriores a fines del III a. E. ${ }^{62}$ Sin embargo se trata de fenómenos minoritarios, aislados y sin continuidad. A partir del siglo II a. E., a cambio, por vez primera las inscripciones públicas se generalizan.

\subsection{El modelo romano: proyección italiana y provincial}

Roma, que vive en esta época una eclosión de la cultura escrita y literaria, ${ }^{63}$ ejemplifica a la perfección el incremento y la diversificación de la pro-

55 Paci 1995, 32-33.

56 Mennella 1995.

57 Prag 2018.

58 CIS 144; Briquel Chatonnet 2018, 124.

59 Correa y Guerra 2019, y E. Luján en este mismo volumen.

60 Poccetti 2018, 76-80.

61 Feruglio 2003; Benelli 2018, 100-101.

62 Velaza 2018, 172.

63 Hacia 240 a. E. se data la traducción de una tragedia griega por Livio Andrónico; en 181 a. E., el primer uso del papiro en Roma - el papiro Derveni-; en 167 a. E., el traslado a la capital por L. Emilio Paulo de la primera gran biblioteca helenística, la del rey Perseo. A fines del I a. E. se abren las primeras bibliotecas públicas: la de Asinio Polión, también en parte botín de guerra oriental, en 39 a. E. y la de Augusto en 28 a. E.; una síntesis en Pesando 1994. 
ducción epigráfica y, en particular, el desarrollo de las inscripciones públicas sobre soportes pétreos. ${ }^{64}$ En los siglos II y I a. E. surgen o se desarrollan nuevos tipos epigráficos que comparten la búsqueda de la publicidad mediante la ubicación en lugares frecuentados y la selección de soportes monumentales. Si con anterioridad estas inscripciones son pocas, escasamente prominentes y restringidas casi al ámbito religioso, ${ }^{65}$ ahora surgen o se desarrollan otros tipos: los pedestales honoríficos de estatua dedicados a personas en vida, desconocidos antes del II a. E.; ${ }^{66}$ hitos terminales relativos a repartos de tierras o miliarios documentando la construcción de vías; ${ }^{67}$ inscripciones vinculadas con los triunfos y el botín de guerra; ${ }^{68}$ epígrafes conmemorando la construcción de edificios; $o$, decisiones de comicios, senado y magistrados grabadas en placas de bronce. ${ }^{69}$ Tipos todos estrechamente ligados en origen a las familias aristocráticas senatoriales. ${ }^{70}$ Esta búsqueda de notoriedad se aprecia también en las inscripciones funerarias, cuya contemplación hasta entonces reservada a los frecuentadores de los sepulcros, forzosamente no muy numerosos, se amplía a partir de mediados del II a. E. al ubicarse en el exterior, ${ }^{71}$ a la vista de todos, una tendencia en la que los libertos desempeñan un papel muy activo a partir del siglo I a. E. ${ }^{72}$

No es este el lugar para profundizar en esta nueva orientación de la epigrafía latina que responde sin duda a circunstancias específicas y difícilmente generalizables al resto de Italia o de occidente por estar vinculadas al papel hegemónico de Roma. Pero conviene al menos destacar dos factores que la fomentan. Por un lado, el extraordinario desarrollo edilicio, urbano y monumental que experimenta la ciudad gracias a las inmensas riquezas acarreadas por la expansión imperial y, además, de carácter innovador merced a la intro-

64 Recuérdese que pasarían de 345 en IV-III a 3.217 en II-I a. E., según Solin 1999, 391393; Salomies 2015, 159; y, en Roma, de 19/29 en IV-III a 346/356 en II-I a. E., según Panciera 1995, 321.

65 Nonnis 2018.

66 Panciera 2007, 1096-1097; Díaz 2018.

67 Díaz 2015.

68 Díaz 2016.

69 Beltrán 1999b.

70 Sobre el surgimiento y desarrollo de estos tipos véase la síntesis de Beltrán 2015b, 91-95 y 99.

71 Panciera 1995, 328.

72 Beltrán 2004b. 
ducción y la reinterpretación de modelos foráneos, helenísticos sobre todo: ${ }^{73}$ al fin y al cabo, una parte muy relevante de la epigrafía pública está vinculada precisamente a la construcción de edificios y a la erección de monumentos. $Y$, por otro, el deseo de afirmación y autorrepresentación individual de las elites aristocráticas, compitiendo no solo con sus iguales, sino - y este es un factor clave - ante la comunidad cívica que empieza a desempeñar un papel clave en la política tardorrepublicana. ${ }^{74}$ Este deseo de afirmación pública, individual, competitiva y monumental, propio inicialmente de la aristocracia senatorial, lo irán haciendo suyo progresivamente nuevos sectores sociales. ${ }^{75}$

Roma fue el escenario privilegiado por la aristocracia senatorial para su afirmación competitiva, pero no el único. Es cierto que el foro de la capital se encontraba tan atestado de estatuas en 159 a. E. que los censores hubieron de ordenar la retirada de todas aquellas que no hubieran sido decretadas por el senado y el pueblo de Roma, según Plinio el Viejo (Nat. 34.30). Sin embargo, estos nuevos monumentos no se levantaban solo en Roma. ${ }^{76}$ Pedestales de estatua honoríficos de fecha temprana proceden de ciudades italianas como Luna, Fregellae, Tusculum, Aquileia o Telesia. ${ }^{77}$ Según Livio, los censores de 174 a. E. erigieron por vez primera edificios en varias colonias romanas de Italia (Liv. 41.27). El triunfador de Acaya tras la toma de Corinto (146 a. E.), según atestiguan los tituli Mummiani, distribuyó una parte del botín por ciudades no solo de Italia, como las sabinas de Cures, Trebula Mutuesca, Nursia —afectadas por repartos viritanos - y tal vez Fregellae ${ }^{78}$ y Pompeya —en este caso con el epígrafe en lengua osca,$-{ }^{79}$ sino también de las provincias como la colonia romana de Parma, en Cisalpina, y quizá la ciudad de Italica, en

73 Torelli 1983.

74 Este contexto popularis explica bien la multiplicación de la publicitación de leyes sobre placas de bronce como ya señalara Crawford 1996, 33-34.

75 Sobre el contexto en el que cristaliza y se desarrolla la cultura epigráfica romana, Beltrán 2015a, 144-145.

76 Díaz 2016, 53.

77 Díaz 2018, 39-45

78 CIL I², 2930a; según Castren 1978, 121 correspondería a una estatua dedicada a L. Mumio y no a una pieza procedente del botín corintio, opción por la que se inclina Díaz 2016, 54 nota 89.

79 Vet. 61; Martelli 2002:1 · mummis · · kúsúl; de nuevo se plantea la duda de si se trata del pedestal correspondiente a una pieza procedente del botín o a una estatua dedicada a Mumio. 
Hispania Ulterior. ${ }^{80}$ Los términos gracanos relativos a las distribuciones de tierras se reparten por diversos lugares de Italia como Capua, Suessula, Atina de Lucania, Aeclanum o Fani, y por África, ${ }^{81}$ y los miliarios jalonan las vías no solo de diversas regiones de Italia sino de las provincias también: Cisalpina, Sicilia, Galia Narbonense, Hispania Citerior, Cerdeña, Macedonia, Asia. ${ }^{82} \mathrm{La}$ irradiación italiana y provincial de estos nuevos tipos de inscripciones es sin duda un factor clave para explicar la difusión fuera de Roma de la epigrafía pública como lenguaje de comunicación social. En las Hispanias, por ejemplo, se documentan muchas de estas nuevas inscripciones: miliarios, hitos terminales, tábulas de bronce con decisiones de los gobernadores o dedicatorias honoríficas a senadores. Se fechan entre comienzos del II a. E. y época augústea, y suman casi una veintena, una cifra nada desdeñable. Muchos proceden de núcleos urbanos importantes como Tarraco, Emporiae, Carthago Noua o Italica, en los que significativamente se desarrollan las primeras series de epigrafía sepulcral monumental - romanas e ibéricas-, pero también de zonas rurales y contextos indígenas. ${ }^{83}$ Las colonias romanas y las comunidades con asentamientos de ciudadanos, en Italia y en las provincias, se hicieron eco precozmente de este nuevo lenguaje comunicativo monumental y empezaron a replicarlo sobre todo en clave funeraria.

\subsection{Hispania y Galia}

La cultura escrita en Hispania y sobre todo en Galia se hallaba mucho menos desarrollada que en Italia con anterioridad a la conquista romana. Se limitaba a los asentamientos coloniales — todos con un registro epigráfico débil- y al litoral ibérico, en el que hasta el siglo II a. E. se producen solo rótulos sobre instrumentum o documentos sobre láminas de plomo, es decir escritos de carácter privado, aunque en número nada despreciable pues ascienden a unos 650. La debilidad o la falta de tradición escrita en estas regiones propició sin duda que el impacto de la nueva cultura epigráfica romana fuera más acusado.

80 ILLRP, 327-331; CIL I², 628, 629, 631; Díaz 2011, 164-166. La inscripción de Itálica es una copia imperial fragmentaria, por lo que la atribución a Mumio no es absolutamente segura.

81 ILLRP, 467-475

82 Díaz 2015.

83 Díaz 2008, 55-60, 85-98 y 191-197. 
En el ámbito ibérico, pese a las dificultades para datar con precisión los materiales dentro de los siglos II y I a. E., se observa el desarrollo de una epigrafía pública, previamente inexistente salvo algún caso excepcional, que se manifiesta a partir de fines del siglo III a. E. en la acuñación de moneda, una actividad estrechamente tutelada por Roma pero autónoma del resto de las manifestaciones epigráficas, y sobre todo en una epigrafía funeraria con más de 80 testimonios. Estos aparecen dispersos por las regiones del interior, en las que muestran conexiones iconográficas con las tradiciones previas, pero sobre todo se concentran en centros costeros como Sagunto, Ampurias y Tarraco, en donde conviven con epitafios latinos, muchos erigidos por libertos, ${ }^{84}$ en los que claramente se inspiran: incorporan soportes, elementos paleográficos y de maquetación, posiblemente fórmulas y ocasionalmente textos latinos; incluso la abreviatura de la palabra ibérica que parece significar hijo, eban, parece fruto de la influencia romana como lo es también el empleo de árulas para epígrafes religiosos. Menos segura es la existencia de una epigrafía honorífica y edilicia, aunque ciertos indicios en Ampurias, Tarraco y Sagunto podrían apuntar en esta dirección. ${ }^{85}$

También la epigrafía celtibérica, ${ }^{86}$ desarrollada a partir de mediados del siglo II a. E., muestra una clara impronta de la cultura epigráfica latina, aunque distinta de la ibérica - monedas aparte-, una circunstancia que subraya la selectiva aproximación de las comunidades indígenas a los modelos con los que entran en contacto en función de sus propias necesidades y formas de articulación social e ideológica, rasgo este característico de los llamados procesos de 'romanización temprana' que en el plano epigráfico se caracterizan por el uso de las lenguas y las escrituras locales. ${ }^{87}$ Los celtíberos utilizaron una variante de la escritura ibérica nordoriental hasta bien entrado el siglo I a. E., momento en el se constata el empleo del alfabeto latino en una treintena de casos. No comparten tipos significativos con la epigrafía ibérica, pero sí recurren a modelos incuestionablemente romanos como las tesserae hospitales y las tábulas de formato medio y grande, todas ellas de bronce, desconocidas entre los iberos y presentes a cambio en la epigrafía latina republicana de Celtiberia. Estas placas de bronce - solo cuatro de tamaño medio o grande-

\footnotetext{
84 Beltrán 2004b.

85 Al respecto Velaza 2018, y Beltrán 2012; sobre los soportes Simón 2013.

86 Beltrán y Jordán 2016, y en este mismo volumen.

87 Beltrán 1999a; 2003.
} 
son, además de las monedas, las únicas inscripciones públicas junto con una docena de epitafios dispersos por diversos puntos de la región. ${ }^{88}$

El caso galo presenta algún punto de coincidencia con el celtibérico, pues aun siendo ambos vecinos de comunidades alfabetizadas desde los siglos VI-V a. E. -iberos y griegos masaliotas-, cuyos sistemas de escritura terminaron por adoptar, no desarrollaron una cultura escrita hasta el siglo II a. E. y vinculada, según todos los indicios, a la presencia romana.$^{89}$ Como en los casos previamente examinados, el contacto con la cultura epigráfica latina, aunque motivó préstamos e incorporaciones diversas, no se tradujo en una asimilación servil de los modelos romanos, sino en su puesta al servicio de las necesidades locales. El desarrollo de la epigrafía pública galo-griega sobre piedra, con unos 80 testimonios funerarios y religiosos, ha sido relacionado a través de indicadores onomásticos y formularios, entre otros, con la presencia de población itálica en la región..$^{90}$ A partir del siglo I a. E., el influjo romano se hace todavía más evidente por la adopción del alfabeto latino y la influencia formal en la técnica epigráfica, aunque sin epígrafes bilingües ${ }^{91} \mathrm{y}$ con muchas menos inscripciones sobre piedra que en la época galo-griega - unas 30-, seguramente porque la epigrafía pública tiende ahora a expresarse en latín. Se exceptúan casos culturalmente tan marcados como los calendarios religiosos de Coligny y Villards d'Héria (RIG III), con una clara influencia romana en la elección del soporte - que en Roma no suele destinarse a propósitos religiosos- y en la disposición formal, similar a la de los fasti romanos, ${ }^{92}$ pese al indigenismo evidente de sus contenidos. La epigrafía pública gala sobre piedra tiene bastante relevancia - un centenar de inscripciones en total $-{ }^{93}$ con un buen número de inscripciones funerarias, pero también religiosas - una veintena-, muchas monumentales y procedentes de santuarios a diferencia de lo que ocurre con la epigrafía paleohispánica en donde las inscripciones religiosas monumentales brillan por su ausencia. ${ }^{94}$

En las tres culturas epigráficas provinciales examinadas - ibérica, celtibérica y gala - la impresión es la misma: el impacto de la presencia romana

88 Beltrán 2018; sobre las téseras de hospitalidad véase Beltrán et al. 2020.

89 Mullen 2013.

90 A. Mullen y C. Ruiz Darasse en este mismo volumen.

91 Estarán 2016, 89 recoge solo dos casos.

92 Woolf 1998, 230 n. 107; difiere en parte Fisher 2016, espec. 278-385.

93 Mullen y Ruiz Darasse 2018, 35-37 y en este mismo volumen.

94 De Tord 2017 y e. p.; Beltrán 2013. 
contribuye al desarrollo de la cultura escrita en general y epigráfica en particular, ex novo en los casos celtibérico y galo, pero sin producir una imitación servil sino una selección de estímulos en el marco de un contexto común de expansión social y geográfica de la escritura, intensificación de su empleo y desarrollo de una escritura pública y monumental, que se aprecia con mayor nitidez en los casos ibérico y galo que en el celtibérico, pero con marcadas diferencias de selección: funeraria en el ámbito ibérico, funeraria pero también religiosa en el galo - en ambos casos privilegiando soportes pétreos- y sobre placas de bronce con contenidos normativos en Celtiberia.

El último caso que debe considerarse es el lusitano, en el que la relevancia de los modelos romanos es palmaria por el empleo del alfabeto latino, por la frecuencia de textos bilingües - tres- en el menguadísimo corpus de seis inscripciones y por la inclusión de teónimos flexionados en lusitano en inscripciones latinas, todas ellas religiosas. ${ }^{95}$

Desafortunadamente resulta muy difícil precisar los ritmos cronológicos de estos desarrollos epigráficos que, al menos en Hispania, parecen corresponder más bien a las postrimerías del II y sobre todo al siglo I a. E. Lógicamente no cobran arraigo en las provincias los tipos públicos más novedosos desarrollados por la aristocracia senatorial, sino otros que comparten con aquellos lo esencial, es decir el deseo de afirmación individual a través de medios escritos, monumentales, permanentes y públicos, pero generando respuestas diferentes: epígrafes funerarios entre iberos y galos -en el caso ibérico con el modelo local de los latinos realizados por libertos- $-{ }^{96}$ religiosos también en las Galias o normativos en la Celtiberia.

La gran novedad es la inversión por las elites indígenas de recursos notables para afirmar esa individualidad en un contexto desestructurado por la conquista, con presencia de población romana, itálica y libertina en núcleos costeros e interiores, y carente de una tradición escrita relevante o de modelos urbanos monumentales preexistentes. Todos estos factores parecen haber potenciado el impacto de la cultura escrita romana y en particular el recurso a la escritura pública como instrumento de afirmación, aunque con expresiones fuertemente originales que se expresan en la lengua y la escritura locales.

95 Wodtko 2017 y su contribución en este volumen; también De Tord 2019; Estarán 2016, 249-292.

96 Beltrán 2004b. 
En todos los casos examinados el único modelo presente en tierras provinciales al que puede recurrirse para explicar la difusión de la epigrafía pública por Hispania y Galia es el romano.

\subsection{Italia}

Las culturas epigráficas italianas, quizá por contar muchas de ellas con relevantes tradiciones escritas previas, reaccionaron frente a los modelos epigráficos romanos de una forma a veces menos receptiva que las provinciales. Esta reacción muestra interesantes concomitancias con la que provocaron en Italia los nuevos modelos urbanísticos y arquitectónicos desarrollados coetáneamente en Roma, algo perfectamente comprensible pues la epigrafía pública forma parte del paisaje monumental y edilicio de una ciudad.

La actividad constructiva en las regiones más dinámicas de Italia —Etruria, Lacio, Campania - se había concentrado en los siglos IV-III a. E. en los edificios de culto y las fortificaciones. En el curso del siglo II a. E., Roma se aparta de esta dinámica y emprende una novedosa renovación urbanística, en buena parte de inspiración helenística, con la introducción de nuevos tipos de edificio -fornices, porticus, basilica, macellum... - promovidos por la competencia edilicia entre miembros de la aristocracia senatorial y con frecuencia vinculados a los triunfos y las victorias militares. Un fenómeno, por tanto, que presenta estrechos paralelismos con los nuevos tipos epigráficos públicos. Estas novedades urbanísticas, sin embargo, apenas tienen proyección fuera de Roma, en donde, a la antigua usanza, la actividad edilicia se concentra en los santuarios y edificios sacros, promovida por las aristocracias locales que afirman con ello su posición social consuetudinaria ante sus comunidades y frente Roma, sin que se observe esa competencia política de la aristocracia senatorial expresada a través de la edilicia tan característica de la Urbs, ${ }^{97}$ que solo parece encontrar un cierto eco, aunque en un contexto religioso más tradicional, en los grandes santuarios sabélicos del sur como el de Pietrabbondante al que enseguida se aludirá.

Una respuesta similar parece operarse en el terreno epigráfico, con un considerable incremento en el uso de la escritura, pero sin una orientación tan marcada hacia la exhibición pública como la perceptible en Roma y, mucho más tímidamente, en puntos de Hispania o Galia. El incremento en la producción epigráfica es claro en muchas áreas. Ya se ha señalado más arriba

\footnotetext{
97 Torelli 1983.
} 
como no menos de 8.000, sobre un total de 10.000 inscripciones etruscas, se datan a partir del siglo III a. E. y aunque no exista una cuantificación similar para otras áreas de Italia, ${ }^{98}$ parece apreciarse también un incremento en las áreas sabélicas, pues de este periodo datan por ejemplo los conjuntos de los santuarios de Pietrabbondante y Rossano di Vaglio, aunque es cierto que en otras áreas la práctica epigráfica paleoeuropea cesa a mediado del II a. E. como ocurre en el Bruzio. ${ }^{99}$

La epigrafía etrusca, continuadora de una tradición multisecular de enorme potencia y copiosísima producción - solo en I a. E. las inscripciones latinas superan en número a las etruscas coetáneas-, mantiene una orientación similar a la de los siglos previos. Dominan de manera abrumadora las inscripciones funerarias, ahora con una producción masiva pero de baja calidad en la Etruria septentrional, casi siempre situadas en el interior de las tumbas, de acceso muy restringido o incluso invisibles, con la excepción de los signáculos externos inscritos de algunas necrópolis, cuya condición pública se ve obstaculizada por una ubicación sobre el soporte que no facilita su lectura: en ciudades como Caere que desarrollan una epigrafía funeraria mucho más visible se recurre al latín, que en el sur se impone rápidamente en detrimento del etrusco tras la Guerra Social. ${ }^{100}$ Es cierto que en el ámbito de la epigrafía religiosa, tradicionalmente sobre pequeños objetos, sí puede identificarse ahora un pequeño grupo de epígrafes monumentales sobre soportes pétreos que constituyen probablemente la única innovación etrusca de matriz romana. ${ }^{101}$

Frente la impermeabilidad etrusca a las influencias externas, las diferentes culturas epigráficas sabélicas parecen mostrarse más abiertas a los estímulos exteriores, sobre todo griegos y romanos, de manera que se incorporan en la fase reciente, IV-I a. E., tipos nuevos como las defixiones en el área tirrénica, las inscripciones viarias de Campania, los epitafios en Campania y Lucania, los epígrafes edilicios en Campania o las inscripciones monumentales en los santuarios. En particular las de Pietrabbondante y Rossano di Vaglio, sobre todo en II a. E., muestran tendencias monumentales y consignan con frecuencia los nombres de los miembros de las elites locales responsables de las construccio-

98 En el área mesápica, cuya epigrafía se desarrolla entre VI y II/I a. E., el mayor incremento se produce en III, coetáneamente al inicio del proceso de romanización, véase

S. Marchesini en este mismo volumen.

99 Poccetti 2018.

100 Benelli 2018 y 2020, 39-41 para este periodo.

101 Benelli 2018, 105. 
nes que muestran una actitud comparable, a escala local, con la competitividad epigráfica senatorial de la Roma coetánea. Algunas innovaciones tienen clara matriz romana como los epitafios poéticos del área peligna y marrucina del siglo I a. E. o los formularios edilicios de obras públicas. ${ }^{102}$ Frente a la orientación manifiestamente privada de la epigrafía sabélica durante la fase arcaica, exceptuados los monumentos funerarios sud-picenos, en las centurias finales de la fase reciente se observa no solo una notable diversificación de los tipos epigráficos, sino la emergencia de varias clases de inscripciones orientadas a una contemplación pública, algunas de ellas claramente influidas por tipos romanos.

En las áreas sabélicas en las que la tradición epigráfica local parece casi perdida, como ocurre en la zona medio-adriática comprendida entre Pisaurum y Hadria, es la cultura epigráfica latina a partir de los nuevos asentamientos romanos la que toma el relevo, primero, a lo largo del III a. E., con baja intensidad y centrada en la esfera sacra, y después con mayor intensidad a partir del siglo II a. E. con nuevos tipos epigráficos, entre los que el funerario no se desarrolla hasta el siglo I a. E. Resulta significativo que, en la colonia siracusana de Ancona, fundada en el siglo IV a. E., estén documentados epitafios sobre piedra desde los orígenes hasta el siglo I a. E. sin que ello estimulara el surgimiento de una epigrafía funeraria local que solo se activa en I a. E. y a partir de modelos romanos. ${ }^{103}$

En términos generales, la intensificación epigráfica es manifiesta en casi toda Italia, mientras que la diversificación $-\mathrm{y}$ sobre todo la epigrafía pública- presenta una incidencia regional variable y resulta poco perceptible en áreas conservadoras en este terreno como Etruria. En cualquier caso el prestigio de la lengua de Roma se traduce en el uso ocasional del alfabeto latino para anotar las lenguas locales entre etruscos, oscos, umbros, faliscos y vénetos, ${ }^{104}$ en la realización de inscripciones bilingües entre oscos (III-I a. E.), vénetos (II-I a. E.), galos cisalpinos y etruscos (sobre todo, II-I a. E.), ${ }^{105}$ y en la proliferación de inscripciones latinas.

Aunque haya escenarios como algunos de los señalados en el área sabélica en los que la orientación hacia lo público de la cultura escrita sea tan manifiesta

102 Poccetti 2018.

103 Paci 1995, 36-37.

104 I. Simón en este mismo volumen.

105 Estarán 2016, 39-40. 
como en las culturas epigráficas provinciales de Hispania y Galia, el peso de las tradiciones locales parece imponerse sobre las nuevas tendencias, que cuando se expresan no lo hacen ya en la lengua vernácula sino directamente en latín. Recuérdese que en el siglo III a. E. dejan de documentarse por escrito algunas lenguas sabélicas como el hérnico o el volsco, a las que se suman a lo largo del II a. E. el falisco, el umbro y el mesápico —este quizá en el I a. E.—, ${ }^{106}$ y en la centuria siguiente casi todas las demás con las únicas excepciones del etrusco y el osco. ${ }^{107}$ No obstante son necesarios más estudios específicos sobre las últimas fases de las epigrafías paleoeuropeas de Italia para poder realizar una valoración más precisa de estas dinámicas.

\section{A modo de conclusión}

En definitiva, a partir de fines del siglo III a. E., en paralelo a la consolidación de la hegemonía romana en Italia y a la expansión por Hispania y Galia, se observa en la cultura escrita del occidente europeo, al menos en la epigráfica, un claro proceso de intensificación, expansión geográfica $-y$ social $-y$ diversificación, que incluye una orientación pública casi desconocida hasta entonces. La comprensión de este proceso requiere todavía de más estudios regionales específicos y de reflexiones similares aplicadas a otras áreas mediterráneas coetáneas; sin embargo, resulta posible fijar algunas líneas de fuerza en su evolución.

La influencia de Roma en este proceso, íntimamente ligado al desarrollo urbanístico y monumental que encabeza la capital, parece fuera de toda duda en lo que respecta a la creación de un marco político común a todos estos territorios, en la difusión de ciertas pautas ideológicas o de comportamiento social, y en el fomento de la conectividad económica y humana. ${ }^{108}$ Sin embargo no se manifiesta de forma homogénea como en el Principado. Roma difunde nuevas tendencias de diferente procedencia y previamente reelaboradas en ese gran crisol cultural en el que la ciudad se convierte en II a. E. Y estas suscitan respuestas diferentes entre las comunidades locales en función de sus características y necesidades. Áreas con prestigiosas y antiguas tradiciones

106 Morandi 2017, 292.

107 Para la cronología de cada una de estas culturas epigráficas pueden consultarse las fichas del banco de datos AELAW (<http://aelaw.unizar.es/database/languages $>$ ) y las respectivas contribuciones a este volumen.

108 Así parece reconocerlo por ejemplo Prag 2018, 141: “There is a strong case to be made that Roman rule was the catalyst for that growth [scil. 'of urban hellenistic culture'], although not the source of the epigraphic and urban culture". 
escritas, como Etruria o la Sicilia griega, se muestran casi impermeables a las nuevas tendencias. Otras, previamente ágrafas y de limitado desarrollo urbano, incorporan más fácilmente los nuevos lenguajes y medios de comunicación, siempre adaptados a las circunstancias y expresados en la lengua y la escritura tradicionales, como ocurre en algunas zonas sabélicas, Hispania o Galia. En muchas de estas, además, fue la presencia romana la que estimuló el surgimiento de la cultura escrita - como en la Galia, en Celtiberia o en Lusitania- pero también la desaparición de otras preexistentes, suplantadas por la latina, como en Umbría y otras áreas sabélicas más afectadas por los asentamientos de población romana.

La aparición de la epigrafía pública, que requiere una inversión económica notable por parte del comitente, supone recurrir por primera vez a la escritura como medio de comunicación de masas, aunque sea de manera incipiente. En Occidente, este nuevo lenguaje alcanza su máxima expresión en Roma, por obra de la competitiva aristocracia senatorial que difundió estos tipos monumentales, innovadores y ligados a la renovación urbanística de la capital, por Italia y las provincias. Las elites locales, los emigrantes romanos y otros grupos sociales como los libertos asumieron este nuevo lenguaje en la medida de sus posibilidades, expresando sobre todo en el terreno funerario y religioso el deseo de afirmación individual. Esta orientación pública de la escritura en la República tardía pone de manifiesto el nuevo papel que desempeña la comunidad — cívica sobre todo-, principal receptor de los mensajes emanados de sus competitivas elites y de las decisiones adoptadas por magistrados y consejos, o protagonista ella misma del mensaje en el caso de las leyendas monetales.

Esta fase de renovación y de eclosión de las culturas epigráficas paleoeuropeas durante los siglos II y I a. E. concluye con su disolución en otra mucho más potente y homogénea, la cultura epigráfica romana del Principado, que, de manera significativa, se desarrolla a partir de Augusto precisamente sobre el substrato epigráfico paleoeuropeo de Italia, Hispania y Galia.

\section{Agradecimientos}

Agradezco a B. Díaz Ariño y M. J. Estarán Tolosa la atenta lectura del manuscrito $y$ las sugerencias realizadas. 


\section{$\begin{array}{llllllllllll}\mathbf{B} & \mathbf{I} & \mathbf{B} & \mathbf{L} & \mathbf{I} & \mathbf{O} & \mathbf{G} & \mathbf{R} & \mathbf{A} & \mathbf{F} & \mathbf{I} & \mathbf{A}\end{array}$}

Adams 2003a: J. N. Adams, "Romanitas and the Latin language", $C l Q u$ 53, 2003, 184-205.

Adams 2003b: J. N. Adams, Bilingualism and the Latin language, Cambridge 2003.

Alföldy 1991: G. Alföldy, "Augustus und die Inschriften: Tradition und Innovation. Die Geburt der imperialen Epigraphik", Gymnasium 98, 289-324.

Amadasi 2019a: M. G. Amadasi Guzzo, "Le fonti epigrafiche”, en: A. Russo, F. Guarneri, P. Xella y J. Á. Zamora (eds.), Carthago. Il mito immortale, Milano 2019, 46-47.

Amadasi 2019b: M. G. Amadasi Guzzo, "L'alfabeto e la scrittura", en: A. Russo, F. Guarneri, P. Xella y J. A. Zamora (eds.), Carthago. Il mito immortale, Milano 2019, 176-177.

Amadasi y Zamora 2013: M. G. Amadasi y J. Á. Zamora, “The Epigraphy of the Tophet”, en: P. Xella (ed.), The Tophet in the Phoenician Mediterranean, Studi Epigrafici e Linguistici 29-30, Verona 2012-2013, 159-192.

Bats 1988: M Bats, "La logique de l'écriture d'une société à l'autre en Gaule méridionale protohistorique", Revue archéologique de Narbonnaise 21, 1988, 121148.

Bats 2004: M. Bats, “Grec et gallo-grec : les graffites sur céramique aux sources de l'écriture en Gaule méridionale (II $\mathrm{II}^{\mathrm{er}}$ s. av. J.-C.)”, Gallia 61/1, 2004, 720.

Bats 2011: M. Bats, "Emmêlements de langues et de systèmes graphiques en Gaule méridionale (VI ${ }^{\mathrm{e}}-\mathrm{I}^{\mathrm{er}}$ siècle av. J.-C.)", en: C. Ruiz Darasse y E. Luján Martínez (eds.), Contacts linguistiques dans l'Occident méditerranéen antique, Madrid 2011, 197226.

Belfiore 2010: V. Belfiore, Il liber linteus di Zagabria, Pisa-Roma 2010.

Bellelli y Benelli 2018: V. Bellelli y E. Benelli, Gli Etruschi. La scrittura, la lingua, la società, Roma 2018.

Beltrán 1995: F. Beltrán (ed.), Roma y el nacimiento de la cultura epigráfica en occidente, Zaragoza 1995.

Beltrán 1999a: F. Beltrán, "Writing, language and society: Iberians, Celts and Romans in northeastern Spain in the $2^{\text {nd }} \& 1^{\text {st }}$ centuries BC", BICS 43, 1999, 131-151.

Beltrán 1999b: F. Beltrán, "Inscripciones sobre bronce: ¿un rasgo característico de la cultura epigráfica de las ciudades hispanas?”, en: XI Congresso Internazionale di Epigrafia Greca e Latina. Atti II, Roma 1999, 21-37.

Beltrán 2003: F. Beltrán, "La romanización temprana en el valle medio del Ebro (siglos II-I a. E.): una perspectiva epigráfica", AespA 76, 2003, 179-191.

Beltrán 2004a: F. Beltrán, "El latín en la Hispania romana: una perspectiva histórica", en: R. Cano (ed.), Historia de la lengua española, Barcelona 2004, 83-106.

Beltrán 2004b: F. Beltrán, “Libertos y cultura epigráfica en la Hispania republicana”, en: F. Marco, F. Pina y J. Remesal (eds.), Vivir en tierra extraña: emigración e integración cultural en el mundo antiguo, Barcelona 2004, 151-175.

Beltrán 2011: F. Beltrán, "Lengua e identidad en la Hispania romana", PalHisp 11, 2011, 19-59.

Beltrán 2012: F. Beltrán, "Roma y la epigrafía ibérica sobre piedra del nordeste peninsular", PalHisp 12, 9-30.

Beltrán 2013: F. Beltrán, "Almost an oxymoron: Celtic gods and Palaeohispanic epigraphy. Inscriptions, sanctuaries and monumentalisation in Celtic Hispania", en: W. Spickermann (ed.), Keltische Götternamen als individuelle Option?, Rahden 2013, 165-184.

Beltrán 2015a: F. Beltrán, "The Epigraphic Habit in the Roman World”, en: Ch. Bruun y J. Edmonson (eds.), The Oxford Handbook of Roman Epigraphy, Oxford-New York 2015, 131-148. 
Beltrán 2015b: F. Beltrán, “Latin Epigraphy: the Main Types of Inscriptions”, en: Ch. Bruun y J. Edmonson (eds.), The Oxford Handbook of Roman Epigraphy, Oxford-New York 2015, 89-110.

Beltrán 2017: F. Beltrán, “Acerca del concepto de romanización”, en: T. Tortosa y S. Ramallo (eds.), El tiempo final de los santuarios ibéricos en los procesos de impacto y consolidación del mundo romano, Madrid 2017, 17-26.

Beltrán 2018: F. Beltrán, "Reflexiones sobre el nacimiento de la epigrafía pública en Hispania. ¿Un fenómeno de matriz romana o respuesta a una tendencia general mediterránea?", en: F. Beltrán y B. Díaz (eds.), El nacimiento de las culturas epigráficas en el Occidente mediterráneo: modelos romanos y desarrollos locales (II-I a. E.), Madrid 2018, 157-168.

Beltrán e. p.: F. Beltrán, "Latinization, citizenship and epigraphic habit", en: A. Mullen (ed.), Transformations of the Roman West: Social Factors in Latinization, en prensa.

Beltrán y Díaz 2018: F. Beltrán y B. Díaz (eds.), El nacimiento de las culturas epigráficas del Occidente mediterráneo. Modelos romanos y desarrollos locales (III-I a. E.), Madrid 2018.

Beltrán et al. 2020: F. Beltrán, B. Díaz, C. Jordán e I. Simón, “Tesseram conferre. Etruscan, Greek, Latin, and Celtiberian tesserae hospitals", Historia 69/4, 2020, 482-518.

Beltrán y Estarán 2011: F. Beltrán y M. J. Estarán, “Comunicación epigráfica e inscripciones bilingües en la Península Ibérica", en: C. Ruiz Darasse y E. Luján (eds.), Contacts lingüistiques dans l'Occident méditerranéen Antique, Madrid 2011, 9-25.

Beltrán y Jordán 2016: F. Beltrán y C. Jordán, Celtibérico. Lengua, escritura, epigrafía, Zaragoza 2016.

Beltrán y Velaza e. p.: F. Beltrán y J. Velaza, "Presencia y testimonios lingüísticos itálicos en Hispania: viejas y nuevas evidencias”, en: E. Benelli, S. Marchesini y P. Poccetti (eds.), Per una definizione delle lingue e culture sabelliche, Roma en prensa.

Benelli 2018: E. Benelli, "Il paesaggio epigráfico tardoetrusco fra tradizione e innovazione", en: F. Beltrán y B. Díaz (eds.), El nacimiento de las culturas epigráficas del Occidente mediterráneo. Modelos romanos y desarrollos locales (III-I a. E.), Madrid 2018, 99-106.

Benelli 2020: E. Benelli, Etrusco. Lingua, scrittura, epigrafía, Zaragoza 2020.

Bietti Sestieri, De Sanctis y La Regina 1990: A. M. Bietti Sestieri, A. De Sanctis y A. La Regina, "Elementi di tipo cultuale e doni personali nella necropoli laziale di Hostería dell'Osa", ScAnt 34, 1989-1990, 65-88.

Boffa 2015: G. Boffa, "Il vaso ben levigato. Una proposta di lettura per la iscrizione più antica dalla necropoli di Osteria dell'Osa", PP 70, 2015, 153-189.

Briquel Chatonnet 2018: F. Briquel Chatonnet, "Lépigraphie publique dans le monde punique", en: F. Beltrán y B. Díaz (eds.), El nacimiento de las culturas epigráficas del Occidente mediterráneo. Modelos romanos y desarrollos locales (III-I a. E.), Madrid 2018, 121-130.

Castren 1978: L. P. Castren, "Some aspects of the life of L. Mummius Achaicus", Arctos 12, 1978, 115-123.

Colonna 2005: G. Colonna, intervención en G. Bartoloni y F. Delpino, Oriente e Occidente: metodi e discipline a confronto. Riflessioni sulla cronología delletà del ferro in Italia, Pisa 2005, 478-483.

Colonna 2014: G. Colonna, "Il graffito di Villa Altieri sull'Esquilino: la piu antica iscrizione da Roma (e un'altrimenti sconosciuta área sacra)”, en: G. Baldelli y F. Lo Schiavo (eds.), Amore per l'antico. Dal Tirreno all'Adriatico, dalla Preistoria al Medioevo e oltre. Studi di antichità in ricordo di Giuliano de Marinis, I, Roma 2014, 15-23. 
Correa y Guerra 2019: J. A. Correa y A. Guerra, "The epigraphic and linguistic situation in the south-west of the Iberian peninsula", en: A. G. Sinner y J. Velaza (ed.), Palaeohispanic Languages and Epigraphies, Oxford 2019, 109-137.

Crawford 1996: M. H. Crawford, Roman Statutes, London 1996.

D’ Andrea 2014: B. D’Andrea, I tofet del Nord Africa dall'età arcaica alletà romana (VIII sec. a. C. - II sec. d. C.). Studi archeologici, Pisa-Roma 2014.

De Hoz 2010: J. de Hoz, Historia lingüística de la Península Ibérica en la Antigüedad. I. Preliminares y mundo meridional prerromano, Madrid 2010.

De Simone y Marchesini 2002: C. de Simone y S. Marchesini, Monumenta linguae Messapicae, Wiesbaden 2002.

De Tord 2017: G. de Tord, "Estudio comparativo de la epigrafía religiosa paleohispánica y gala", PalHisp 17, 2017, 279-289.

De Tord 2019: G. de Tord, "Particularidades de la epigrafía lusitana: ¿comparte elementos con otras culturas o es un unicum?”, en J. Tomás García y V. Del Prete (eds.), Imágenes, lengua y creencias en la Lusitania romana, Oxford 2019, 36-53.

De Tord e. p.: G. de Tord, Epigrafía religiosa en lenguas locales del Occidente mediterráneo, en preparación.

De Santis y Rossi 2019: A. M. De Santis e I. Rossi (eds.), Crossing Experiences in Digital Epigraphy. From Practice to Discipline, Varsovia-Berlín 2019.

Díaz 2011: B. Díaz, "Epigrafía y gobernadores provinciales en Hispania durante la República Romana", Chiron 41, 2011, 149-179.

Díaz 2015: B. Díaz, Miliarios romanos de época republicana, Roma 2005.

Díaz 2016: B. Díaz, "El papel de la Epigrafía en la construcción de la imagen pública de la Aristocracia romana en época republicana: inscripciones y botín de guerra”, en: F. Marco, F. Pina y J. Remesal (eds.), Autorretratos. La creación de la imagen personal en la Antigüedad, Barcelona 2016, 41-58.

Díaz 2008: B. Díaz, Epigrafía latina republicana de Hispania, Barcelona 2008.

Díaz 2018: B. Díaz, "El origen de la epigrafía honorífica romana”, en: F. Beltrán y B. Díaz (eds.), El nacimiento de las culturas epigráficas del Occidente mediterráneo. Modelos romanos y desarrollos locales (III-I a. E.), Madrid 2018, 35-54.

Estarán 2016: M. J. Estarán, Epigrafía bilingüe del Occidente romano. El latín y las lenguas locales en las inscripciones bilingües y mixtas, Zaragoza 2016.

Estarán 2019: M. J. Estarán, “iHablantes de lenguas itálicas en Hispania? Un análisis onomástico y sociolingüístico de la epigrafía latina hispana del siglo II a. C.", Athenaeum 107, 2019, 388-423.

Estarán e. p.: M. J. Estarán, "Learning the Latin alphabet. Alphabet switching and graphemic adaptation in the Western Mediterranean (first century BCE to first century CE)", en: N. Moncunill Martí y M. Ramírez Sánchez (eds.), Aprender la escritura, olvidar la escritura. Nuevas perspectivas sobre la historia de la escritura en el Occidente romano, Vitoria en prensa.

Feruglio 2003: A. E. Feruglio, "Le necropoli etrusche”, en: G. M. della Fina (ed.), Storia di Orvieto. I. Antichità, Perugia 2003, 275-328.

Fisher 2016: J. Fisher, "Becoming Gallic: Orality, Voice and Identity in Roman Gaul”, en: N. W. Slater, Voice and Voices in Antiquity, Leiden-Boston 2016, 377-395.

Gorrochategui y Vallejo 2019: J. Gorrochategui y J. M. Vallejo, “The parts of Hispania without epigraphy”, en: A. G. Sinner y J. Velaza (ed.), Palaeohispanic Languages and Epigraphies, Oxford 2019, 335-364. 
Gorrochategui e. p.: J. Gorrochategui. Vascónico-aquitano. Lengua, escritura, epigrafía, Zaragoza en prensa.

Keay 2013: S. Keay, “Were the Iberians hellenised?”, en J. Prag y J. C. Quinn (eds.), The Hellenistic West. Rethinking the Ancient Mediterranean, Cambridge 2013, 300-318.

La Regina 2012: A. La Regina, "Vaso con iscrizione dell'VIII secolo a. C.”, en: R. Friggeri, M. G. Granino Cecere y G. L. Gregori, Terme di Diocleziano, la collezione epigrafica, Roma 2012, 100-101.

Lambert 1994: P.-Y. Lambert, La langue gauloise, Clamecy 1994.

Lambert 1998a: P.-Y. Lambert, “La tuile gauloise de Châteaubleau (Seine-et-Marne)”, Études Celtiques 34, 1998, 57-115.

Lambert 1998b: P.-Y. Lambert, "Les autres tuiles inscrites de Châteaubleau (Seine-et-Marne)", Études Celtiques 34, 1998, 117-133.

Marchesini 2009: S. Marchesini, Le lingue frammentarie dell'Italia antica: manuale per lo studio delle lingue preromane, Milano 2009.

Martelli 2002: A. Martelli, "Per una nuova lettura dell'iscrizione Vetter 61 nel contesto del santuario di Apolo a Pompei", Eutopia 2, 71-81.

Meiser 2014: G. Meiser (ed.), Etruskische Texte, Editio Minor. I. Einleitung, Konkordanz, Indices; II. Texte, Hamburg 2014.

Mennella 1995: G. Mennella, "Romanizzazione ed epigrafía in Liguria”, en F. Beltrán (ed.), Roma y el nacimiento de la cultura epigráfica en Occidente, Zaragoza 1995, 17-29.

Morandi 2017: A. Morandi, Epigrafia Italica, 2 vols., Roma 2017.

Mullen 2007: A. Mullen, "Evidence for written Celtic from Roman Britain: a linguistic analysis of Tabellae Sullis 14 and 18", Studia celtica 41, 2007, 31-45.

Mullen 2013: A. Mullen, Southern Gaul and the Mediterranean: multilingualism and multiple identities in the Iron Age and Roman periods, Cambridge 2013.

Mullen y Ruiz Darasse 2018: A. Mullen y C. Ruiz Darasse, Gaulish. Language, writing, epigraphy., Zaragoza 2018.

Nonnis 2018: D. Nonnis, "La nascita dell'epigrafia pubblica latina tra VI e II sec. a. C.: alcune osservazioni a margine della documentazione", en: F. Beltrán y B. Díaz (eds.), El nacimiento de las culturas epigráficas del Occidente mediterráneo. Modelos romanos y desarrollos locales (III-I a. E.), Madrid 2018, 15-34.

Paci 1995: G. Paci, "Romanizzazione e produzione epigrafica in area medio-adriatica", en: F. Beltrán (ed.), Roma y el nacimiento de la cultura epigráfica en Occidente, Zaragoza 1995, 31-47.

Panciera 1995: S. Panciera, "La produzione epigrafica di Roma in età repubblicana. Le officine lapidarie”, en: H. Solin, O. Salomies y U. M. Liertz (eds.), Acta colloquii epigraphici Latini: Helsingiae 3.-6. sept. 1991 habiti, Helsinki 1995, 319-342.

Panciera 2007: S. Panciera, "L'epigrafia latina nel passaggio dalla Repubblica all'Impero", en: M. Mayer, G. Baratta y A Guzmán (eds.), Acta XII Congressus Internationalis Epigraphiae Graecae et Latinae, Barcelona 2007, 1903-1106.

Pathuisot 1997: F. Pathuisot, Châteaubleau (Seine-et-Marne) - Site des Grands Jardins: rapport 1997, Châteaubleau 1997.

Pesando 1994: F. Pesando, Libri e biblioteche. Vita e costumi dei romani antichi, Roma 1994.

Poccetti 2018: P. Poccetti, "L'epigrafia sabelica tra varietà local e linguagi comuni”, en: F. Beltrán y B. Díaz (eds.), El nacimiento de las culturas epigráficas del Occidente mediterráneo. Modelos romanos y desarrollos locales (III-I a. E.), Madrid 2018, 71-106. 
Poli 2003: F. Poli, “Un document osque méconnu: le base d’Alésia”, SE 69, 2003, 425-428.

Prag 2013: J. Prag, “Epigraphy in the western Mediterranean: a Hellenistic phenomenon?”, en: J. Prag y J. C. Quinn (eds.), The Hellenistic West. Rethinking the Ancient Mediterranean, Cambridge 2013, 320-347.

Prag 2018: J. Prag., "The birth of epigraphic culture in the Western Mediterranean: Sicilian epigraphic culture in the later Hellenistic period", en: F. Beltrán y B. Díaz (eds.), El nacimiento de las culturas epigráficas del Occidente mediterráneo. Modelos romanos y desarrollos locales (III-I a. E.), Madrid 2018, 131-144.

Remesal y Musso 1991: J. Remesal y O. Musso (eds.), La presencia de material etrusco en la península Ibérica, Barcelona 1991.

Rochette 1997: B. Rochette, Le latin dans le monde grec. Recherches sur la diffusion de la langue et des lettres latines dans les provinces hellénophones de l'Empire Romain, Bruxelles 1997.

Rochette 2010: B. Rochette, “Greek and Latin bilingualism”, en: E. J. Bakker (ed.), A Companion to the Ancient Greek Language, Chichester 2010, 281-293.

Salomies 2015: O. Salomies, “The Roman Republic”, en: Ch. Bruun y J. Edmonson (eds.), The Oxford Handbook of Roman Epigraphy, Oxford-New York 2015, 153-177.

Simón 2013: I. Simón, Los soportes de la epigrafía paleohispánica. Inscripciones sobre piedra, bronce y cerámica, Zaragoza-Sevilla 2013.

Simón 2019a: I. Simón, "La paleografía y datación de la inscripción lusitana de Lamas de Moledo", Mélanges de la casa de Velázquez 49/1, 2019, 159-184.

Simón 2019b: I. Simón, "Sobre la inscripción del mosaico helenístico de Ilici (La Alcudia, Elche)", PalHisp 19, 2019, 123-144.

Simón 2019c: I. Simón, "Lenguas vernáculas de Hispania escritas en alfabeto latino. Un episodio particular de la latinización”, Athenaeum 107, 2019, 55-93.

Solin 1999: H. Solin, "Epigrafia repubblicana. Bilancio, novità, prospettive", en: XI Congresso Internazionale di Epigrafia Greca e Latina. Atti II, Roma 1999, 379-404.

Torelli 1983: M. Torelli, "Edilizia pubblica in Italia centrale tra guerra sociale ed età augustea: ideología e classi social", en: Les «bourgeoisies» municipales italiennes aux $I^{e}$ et $I^{\text {er }}$ siècles av. J.-C., Naples 1983, 241-250.

Velaza 2018: J. Velaza, “Epigrafía ibérica sobre soporte pétreo: origen y evolución”, en: F. Beltrán y B. Díaz (eds.), El nacimiento de las culturas epigráficas del Occidente mediterráneo. Modelos romanos y desarrollos locales (III-I a. E.), Madrid 2018, 169-183.

Velaza e. p.: J. Velaza, “La tésera de Armuña de Tajuña (Guadalajara)”, en prensa.

Wodtko 2017: D. Wodtko, Lusitanian. Language, writing, epigraphy, Zaragoza 2017.

Woolf 1996: G. Woolf, "Monumental writing and the expansion of Roman Society in the early empire", JRS 86, 1996, 22-39.

Woolf 1998: G. Woolf, Becoming Roman. The Origins of Provincial Civilization in Gaul, Cambridge 1998.

Zamora 2013: J. A. Zamora, "Novedades de epigrafía fenicio-púnica en la península Iberica y sus aledaños", PalHisp 13, 2013, 359-384.

Zamora 2019: J. A. Zamora, "Phoenician epigraphy in the Iberian península", en: A. G. Sinner y J. Velaza, Palaeohispanic Languages and Epigraphies, Oxford 2019, 56-77. 